\title{
A Reforma do Sistema Eleitoral e Questões Subjacentes
}

\author{
Augusto Terqolina Salton
}

\section{INTRODUÇÃO}

A reforma política é um assunto bastante debatido no Brasil atualmente. Estão inseridas nesse debate diversas Questões, desde a fidelidade partidária, o financiamento público das campanhas eleitorais ou a extensăo do voto facultativo, até a mudança no sistema de governo!. Dentre essas matérias, destaca-se uma Que tramita no Congresso Nacional há alguns anos e é objeto de inúmeras Propostas de Emenda à Constituição (PECS): a reforma do sistema eleitoral.

Os sistemas eleitorais são o conjunto de regras que disciplinam as eleições, determinando a organização territorial, o procedimento de votação, os critérios de apuração, os requisitos para a designação do ou dos candidatos eleitos ${ }^{2}$. Utilizando-se este ou aquele sistema, uma mesma composição de votos pode produzir resultados muito diferentes. Os critérios que levam os votos populares a eleger esses ou aQueles candidatos são o cerne dos sistemas eleitorais.

Analisando-se as propostas, Que em sua esmagadora maioria restringem-se à composição da Câmara dos Deputados, percebe-se que duas são as principais idéias debatidas: a adoção de um sistema distrital ou misto e a manutenção do sistema proporcional. Propostas de menor impacto defendem a mudança da composição da Câmara de Deputados, aconselhando a adoção do sistema majoritário para todo o Poder Legislativo federal. Salientase, porém, a discussão entre a idéia distrital e a idéia proporcional. Esse confronto leva a diversas Questôes, algumas meramente técnicas, outras axiológicas e, até mesmo, ideológicas.

Apenas a título ifustrativo, citam-se as Propostas de Emenda à Constituição Que tramitam no Senado Federal sob os $\pi^{\circ}$ S 31/99, 44/99, 14/2003 - relativas ao voto facultativo - e a de $n^{\circ} 07 / 2004$, propondo a adoção do Sistema Parlamentarista. (Disponível em: <www.senado.govbr>. Acesso em: 9.mar.2005.)

2 Nesse sentido, SILVA, José Afonso da. Curso de direito constitucional positivo. 23. ed. São Paulo: Mallieiros, 2004. p. 367-368. 
O objetivo do presente trabalho é analisar criticamente as idéias subjacentes às Propostas de Emendas à Constituição da República que alteram o sistema eleitoral. Para isso, é necessário estudar os diversos sistemas eleitorais. Inicialmente, serão abordados os dois sistemas eleitorais clássicos: o proporcional e o majoritário. Esse primeiro ponto será desenvolvido em três partes: o funcionamento dos sistemas, o teor da PECs que sobre eles versam e um registro das indagaçôes às Quais eles levam.

Num segundo momento, será analisado o grupo dos sistemas distritais, no qual se inclui o sistema misto. Também serăo abordados o funcionamento desse sistema, o conteúdo das propostas de sua adoção e as Questôes a ele relacionadas. Por fim, num terceiro tópico, serão sintetizados e analisados os problemas que se antepõem à escolha dos sistemas eleitorais e as questões que decorrem da escolha de um sistema eleitoral.

\section{SISTEMA PROPORCIONAL E SISTEMA MAUORITÁRIO}

\subsection{Conceitos e idéias centrais}

O Sistema Majoritário, ou Sistema de Representação Majoritária, tem como critério para definir o candidato eleito o número de votos recebidos por concorrente. Tanto pode ser utilizado em eleições de um só, por exemplo prefeito municipal, nas quais é o candidato mais votado que se elege, como em eleições de vários, por exemplo, para o Senado Federal, em Que se elegem os três mais votados de cada ente da Federação $0^{3}$.

Por sua vez, o Sistema Proporcional, também conhecido como sistema de representação das opiniões ${ }^{4}$, só se aplica às eleições para mais de uma vaga ${ }^{5}$, como é o caso das casas legislativas. Esse sistema visa a conferir a cada partido um número de cadeiras proporcional ao número de votos obtidos ${ }^{6}$, independentemente do número de votos que cada um de seus candidatos receba individualmente. Bastante ilustrativa é a diferenciação elaborada por Paupério:

3 De forma semelhante, SILVA, Curso de direito constitucional positivo, p. 369.

4 BONAVIDES, Paulo. Ciêncla Política. 10. ed. rev. atual. São Paulo: Malheiros, 2003. p. 250.

5 Ferreira Filho salienta, com razâo, Que o sistema proporcional é inviável inciusive para eteiçōes de poucos. (FERREIRA FILHO, Manoel Gonçalves. Comentário à Constituição brasileira de 1988. e. ed. atual. e reformulada. São Paulo: Saraiva, 1997. p. 281, e FERREIRA FILHO, Manoel Gonçalves. Curso de direito constitucional 9. ed. ampl. e atual, e reformulada. São Paulo: Saraiva, 1998, p. 101.)

- Nesse sentido: STRECK, Lenio Luiz e MORAIS, José Luis Bolzan de. Ciência política e teoria geral do estado. 3. ed. Porto Alegre: Livraria do Advogado, 2003, p. 179; DALLARI, Dalmo de Abreu. Elementos de teoria geral do Estado. 20. ed. atual. São Paulo: Saraiva, 1998, p. |9|-192. 
É muito comum comparar o governo com uma torta. No sistema majoritário, se a maioria é constituída de $4 / 7$ do total do eleitorado e a minoria de $3 / 7$, fica a maioria com a torta inteira. Não parece justo. Por isso, acham muitos Que, nesse caso, deve ser a torta dividida em sete partes, ficando a maioria com Quatro e a minoria com três. É o sistema proporcional.?

O Sistema de Representação Proporcional possui inúmeras variaçōes nos critérios de proporção e de aproveitamento das chamadas 'sobras eleitorais'. Isso será visto no item seguinte.

lá o sisterna majoritário possui apenas duas variaçōes: o majoritário simples, de maioria relativa ou de um só turno, em Que basta Que o candidato seja mais votado Que os outros, independentemente do tamanho da superioridade; e o majoritário de dois turnos ou de maioria absoluta, no Qual, caso nenhum candidato obtenha mais Que a metade dos votos válidos, realiza-se um segundo turno apenas entre os dois mais votados, ocasião na Qual Qualquer superioridade será suficiente ${ }^{8}$.

O sistema majoritário simples é aplicado nas eleições para senador e para prefeitos de cidades com até duzentos mil eleitores (art. 29, inciso II, da Constituição da República). Nas eleições para presidente da República, governador e prefeito de municípios com mais de duzentos mil eleitores, adota-se o sistema de maioria Qualificada (arts. 29, inciso II, 28. caput, e 77 da Constituição da República).

O fundamento do sistema majoritário é que, em decisões democráticas, a vontade da maioria deve prevalecer. E isso é perfeitamente coerente com as eleições para um só, especialmente aquelas em Que se exige maioria absoluta ou dois turnos. Entretanto, esse sistema, por vezes, se contradiz Quando a eleição é para mais de um cargo ou ocorre em apenas um turno. Partindo do exemplo do Senado Federal, muitas vezes - para não dizer na maioria das vezes - os senadores são eleitos com votos Que representam uma parcela do eleitorado menor Que a parcela que votou nos outros candidatos, em outras palavras, a minoria se impōe sobre a maioria.

Além disso, o sistema majoritário dificulta aos pequenos partidos a obtenção de cadeiras. Candidatos de agremiações menores não conseguem tantos votos, individualmente, Quanto os de agremiações maiores. Acaba Que a divisão das cadeiras entre partidos grandes e partidos pequenos se dá de forma desproporcional ao tamanho de seus eleitorados, em prejuízo dos menores. Conforme salientam Streck e Morais, bem como Vicente Barreto, muitas vezes, no sistema majoritário, as minorias ficam sem representaçăo".

7 PAUPERIO, A. Machado. Teoria geral do Estado. 6. ed. rev. e ampl. Rio de laneiro, Forense, |97|, p. 237.

8 Da mesma forma, FERREIRA, Luís Pinto. Teoria geral do Estado. 2. ed. rev. ampt. e atualizada. São Paulo: Saraiva, 1975, v. 2, p. 647.

- STRECK e MORAIS, 2003, p. 178; BARRETO, Vicente. Voto c Representação, in Curso de introdução à ciência política, [984, p.50. 
Basicamente com a intenção de corrigir essa distorção, foi desenvolvido o sistema proporcional, cujo principal objetivo é permitir a representação às minorias ${ }^{10}$, não só às minorias, mas a todas as parcelas Que tenham força numérica suficiente para participar ${ }^{11}$.

\subsection{Modalidades de sistemas proporcionais e a solução das sobras}

É possível conceber um sistema eleitoral proporcional de diversas formas. Muitas modalidades foram desenvolvidas, dentre as Quais se citam: o sistema do voto limitado, formulado por Dobraniki, adotado na Inglaterra (1867-1885), na Itália (1882-1891) e em diversos outros países, inclusive no Brasil (|875-1889); o sistema de voto cumulativo, formulado por Barthélemy-Duez e Esmein; o sistema preferencial, de Hare e Andrae; o sistema de concorrência de listas, divulgado por Hagenbach, Esmein e outros; o sistema automático, de Kaisenberg; o sistema de cociente eleitoral, exposto por Duguit ${ }^{12}$.

De todas as modalidades de sistema proporcional, duas se destacam: o sistema do Quociente eleitoral e o sistema do numero uniforme. Pelo sistema do Quociente eleitoral, Que é o adotado no Brasil, o número de vagas a ser preenchido é dividido pelo número de votos válidos. O resultado dessa divisão é o Quociente eleitoral. Por esse critério, cada partido elege tantos candidatos Quantas vezes sua votação atingir o Quociente eleitoral. ${ }^{13}$ Nesse sistema, o Quociente só é conhecido após o término da votação, pois devem ser descontados os votos inválidos.

O sistema do número uniforme, ou sistema do Quociente fixo ou do número único, funciona da mesma forma: a votação de cada partido é dividida pelo Quociente e o resultado é o numero de vagas. ${ }^{14}$ A diferença, apenas, é Que o Quociente é estabelecido previamente à eleição. Daí a denominação de número uniforme ou Quociente fixo. Conforme já mencionado, o Brasil adota o sistema proporcional de Quociente eleitoral por força do disposto no art. 106 da Lei n ${ }^{04.737 / 65 ~-~ C o ́ d i g o ~ E l e i t o r a l . ~}$

Independentemente da modalidade adotada, Quase sempre sobram votos válidos não aproveitados e pelo menos uma cadeira não preenchida. Eis o problema dos restos ou das sobras..$^{15}$ Inicialmente, nas eleições nacionais em Que os votos são computados em

10 Nesse sentido, BONAVIDES, Ciência Política, 2003, p. 250-25 1; STRECK e MORAIS, 2003, p. 179; FERREIRA, 1975, p. 648; DALLAR!, 1998. p. 192;

is Com a mesma posiçäo, BONAVIDES, citando Prélot e Jeanneau, Ciência Politica, 2003, p. 250; AMADO, Gilberto. Eleiçőes e representaçăo. Brasilia: Senado Federal, 1999. p. 58 e p. 61-62; FERREIRA FILHO, 1997, p. 281;

12 MALUF, Sahid. Teoria geral do Estado. 24. ed. rev e atual. / pelo Prof. Miguel Alfredo Malufe Neto - São Paulo: Saraiva, 1998, p. 224.

i3 BONAVIDES, Ciência Política, 2003, p. 253.

34 FERREIRA, op. cit., p. 650.

3 Corroboram essa afirmação BONAVIDES, Ciência Política, 2003, p. 253-254; e FERREIRA, 1975. p.650-651. 
circunscrições - como é o caso das eleiçōes para a Câmara dos Deputados, no Brasil poder-se-iam adotar dois critérios para computar os restos: somar as sobras de todas as circunscrições e resolvê-las nacionalmente, ou resolvê-las dentro de cada circunscriçăo. ${ }^{16}$ No Brasil, a resolução das sobras ocorre dentro das circunscrições.

Independentemente do espaço geográfico no Qual processar as sobras (nacional ou local), faz-se necessário um método para preencher as cadeiras restantes com os votos validos não aproveitados. As principais técnicas são duas: a do Maior Resto e a da Melhor Média.

Pelo método do Maior Resto, também conhecido como 'Sistema Hagenbach', a cadeira restante irá para o partido Que apresentar maior resto. ${ }^{17} \mathrm{Em}$ outras palavras, ganhará a cadeira aQuela agremiação para a Qual faltarem menos votos para atingir novamente o Quociente eleitoral.

A técnica de Melhor Média computa os votos restantes em favor do partido que tiver a melhor média entre o número de votos recebidos e o número de cadeiras obtidas. Ela teve sua manifestação clássica na fórmula matemática desenvolvida por Hondt, Que consiste num complexo cálculo Que permite num só cálculo dividir as cadeiras proporcionalmente já aproveitando os restos. ${ }^{18}$

Entretanto, existem outras formas de calcular as melhores médias, como a fórmula adotada no Brasil, pela Qual para cada partido se divide o número de votos válidos recebidos pelo número de cadeiras por ele obtidas mais uma, ${ }^{19}$ repetindo-se essa operação para as demais cadeiras restantes. Isso está disposto no artigo 109 do Código Eleitoral.

Outros critérios e métodos podem ser desenvolvidos. O fato é Que nenhum critério é imune a críticas porQue, forçosamente, acabará por salientar um ou outro lado de alguma antinomia - partido versus território, partidos pequenos versus partidos grandes. ${ }^{20}$

Ainda Que existam propostas em tramitação no Congresso Nacional Que visem a alterar o funcionamento do sistema proporcional ${ }^{21}$, sem, contudo, alterar sua essência, analisar suas particularidades foge da temática deste trabalho no âmbito em Que é proposta. Compreendidos, em essência, os sistemas proporcional e majoritário, oportuno analisá-los de forma mais detahada, a começar pelos projetos Que tramitam no Congresso Nacional.

16. BONAVIDES, op. cit, p. 254.

17 SOUZA, Sully Alves de, Sistemas Eleitorais, in Curso de introduçăo à ciência política, 1984, p. 82.

18 BONAVIDES, op. cit., p. 254. Para compreender a fórma de Hondt, consultar CAVALCANTI, Themistocles Brandão. Teorta do Estado. Rio de laneiro: Editor Borsoi, 1958, p. 334 e FERRE\}RA, op.cit., p. 652.

19 SOUZA, Sully Alves de, op. cit., p. 81; e BONAVIDES, op. cit., p. 254)

${ }^{20}$ Sobre isso, ler BONAVIDES, Ciência Política, 2003, p. 254.

21 Citam-se os projetos de lei Ordinária de nos 2887/00, 2946/00, 3428/00 e 3949/00, Que propõem o voto em listas, em tramilação na Câmara dos Deputados. Disponível em <www.camara.gov.br> Acesso em: 9.mar. 2005. 


\subsection{Propostas de Emenda Constitucional. Alteraçôes propostas e motivação}

\section{I.3.1 Propostas de adoção de um sistema majoritário}

Tramitam na Câmara dos Deputados as Propostas de Emenda à Constituição de números I08/95, 294/00 e I33/03, pelas Quais as eleiçóes para a Câmara dos Deputados passarian a realizar-se pelo sistema majoritário simples, não mais pelo sistema proporcional. A última dessas propostas - PEC $133 / 03$ - indica a mesma alteração na composição da Câmara de Vereadores.

O principal motivo apresentado por essas propostas é as distorções Que ocorrem no sistema proporcional. Na forma atual, muitas vezes candidatos de determinado partido são eleitos recebendo menos votos Que candidatos de outros partidos Que não são eleitos. Outra distorção apontada é que, em alguns Estados, os candidatos precisam de muito mais votos para se eleger do Que em outros.

Os partidários do sistema majoritário também defendem Que o sistema proporcional desvirtua os partidos políticos Quando esses passam a buscar candidatos não mais por suas opiniōes, isto é, pela sua coerência com o programa partidário, mas por sua provável votação 22 .

\subsubsection{Propostas de manutenção de um sistema proporcional}

Por outro lado, os partidários do sistema proporcional submeteram à Câmara dos Deputados os Projetos de Lei $n^{\circ}$ 1 1 37/2003 e 493/03 - aquela em tramitação, essa arquivada - e as PECs de números 179/95, 170/99, 195/00, 196/00 e 485/02 - todas em tramitação. No Senado Federal tramita a PEC 50/99. Todas essas propostas defendem a manutenção do sistema proporcional; elas apenas visam a corrigir as distorções do sistema atual, sem, contudo, alterar sua orientaçâo, ou seja, sua sistemática proporcional. Pretendem corrigir problemas técnicos, mas sem alterar Questões substanciais e ideológicas.

Uma análise mais acurada demonstra Que o confronto entre esses dois sistemas esconde outras Questões além das já apresentadas.

\subsection{Questóes oue surgem do confronto entre o sistema proporcional e o sistema MajoritáRio}

Conforme foi visto no ponto anterior, a principal Questão Que surge do confronto entre o sistema proporcional e o sistema majioritário é a distorção Quanto ao número de votos necessários para se eleger.

a) Distorção entre Estados. A primeira distorção causada pelo sistema proporcional é a existência de Estados em que o candidato precisa de muito mais votos para

22 PEC 133/03. Disponivel em <mww.camara.gov.br> Acesso em: 9.mar.2005. 
se eleger do Que em outras unidades da Federação. De fato, o sistema proporcional na forma em Que se encontra provoca essa deturpação da representatividade ${ }^{23}$. Conforme salientado por autores como Magalhães ${ }^{24}$, isso fere a igualdade de voto, positivada no artigo 14 , caput, da Constituição da República.

Deve-se, contudo, distinguir dois aspectos da igualdade de voto. De um lado, existe a igualdade formal, facilmente visualizada, Que é a afrontada pelo sistema atual. Trata-se da igualdade numérica, absoluta, pela Qual, se um candidato de um Estado, por exemplo, precisa de trinta mil votos para se eleger ao Congresso Nacional, não é justo Que um candidato de outro Estado precise de, pelo menos, noventa mil votos. Essa distorção faz com Que o povo de estados mais populosos seja menos representado Que o povo de estados menores; os votos daqueles eleitores valem menos Que os votos desses eleitores.

A outra faceta da igualdade, muito mais sutil, é a igualdade na força final do voto, a igualdade na eficácia ${ }^{25}$. Essa igualdade, igualdade substancial, só é obtida pelo sistema proporcional, Que permite que todos os grupos sejam representados no tamanho de suas forças, fato Que não ocorre no sistema majoritário.

Então, simplesmente substituir o sistema atual por um sistema majoritário significa resolver um problema e criar outro; significa promover a igualdade formal e prejudicar a igualdade substancial do voto. De QualQuer forma, para corrigir essa distorção não se faz necessário abandonar o sistema atual, basta aperfeiçoá-lo. E essa é uma Questão muito mais técnica (matemática) do Que jurídica.

b) Distorçăo entre candidatos. A outra distorção apontada diz respeito ao fato de candidatos se elegerem tendo recebido muito menos votos Que candidatos Que não se elegem ${ }^{26}$. De fato isso ocorre. Se o partido A atingiu quatro vezes o quociente eleitoral e um de seus candidatos sozinho trouxe mais da metade dos votos, é bem provável Que a Quarta cadeira desse partido vá para um candidato Que tenha tido uma votação pessoal muito pequena. Paralelamente, é possível que um candidato do partido $B$ tenha uma alta votação. maior Que a do Quarto eleito pelo partido $A$, mas seu partido não atinja o Quociente eleitoral e ele não se eleja.

${ }^{23}$ STRECK, Luiz Streck. Hermenêutica lurídica e(m) Crise. 5. ed. rev. atual. Porto Alegre: Livraria do Advogado, 2004, p. 35.

24 'O outro fato importante consiste em lembrarmos a imperfeição do modelo adotado de representação dos Estados na Câmara Federal de Deputados, onde se estabeleceu como número mínimo de representantes por Estados, oito depulados, o número máximo, setenta deputados. Este dispositivo constitucional não permite o cumprimento de princípio conslitucional de igualdade jurídica, eue se estende aos direitos políticos em sentido restrito para significa[sic] um eleitor um voto. Ao se estabelecer a circunscriçăo por Estado e se eslabelecer número mínimo e máximo sem nenluurn critério matemático de proporcionalidade ou de peso de voto, temos que o voto do eleitor de Estado muito populosos[sic] como São Paulo, Minas Gerais, Rio de Janeiro, Rio Grande do Sul, Bahia, vale muito menos que o voto dos eleitores de Rondônia, Roraima, Amapá, Acre, Sergipe.' (MAGALHÃES, losé Luiz Quadros de. Debates de direito eleitoral. Belo Horizonte: Movinento Editorial Faculdade de Direito da UFMG, 1997, p. 50)

${ }^{25}$ Essa igualdade é bem desenvolvida por BONAVIDES, Ciência Política, 2003. p. 250-251.

${ }^{26}$ Com a mesma alirmação, MAGALHÃES, 1997, p. 44. 
Neves:

Quanto a essa Questão, é oportuno transcrever as palavras do então senador Tancredo

Ninguém deve se impressionar com o fato de que, no regime presidencial um deputado tenha $200,300,500.000$ votos, e outros sejam eleitos com $30.000,20.000$ e até por 10.000 votos, como tem acontecido na vida pública brasileira. Por Quê? Porque esse voto pertence ao partido. O partido tem o direito de distribuí-lo. E a lei e o regulamento, de maneira a mais feliz, fazem com que esse voto, que é do partido, seja pelo partido distribuído realmente entre os seus adeptos, entre os candidatos que sob sua legenda pleitearam o voto popular. Enão há prejuízo para ninguém. Esses votos, se não fossem realmente subdividos entre os diversos companheiros de chapa do altamente eleito, estariam esterilizados, o Que seria uma injustiça, uma calamidade pública [sic]. ${ }^{27}$

c) Representação de minorias. Intimamente ligada às Questões anteriores está a representação das minorias, ou, de uma forma melhor, a representação das parcelas significativas do eleitorado. Conforme já exposto no item 2.1., o sistema majoritário peca por prejudicar a participação de parcelas menores da população.

Interessante notar, antes de mais nada, Que alguns opositores mais afoitos combatem a representação proporcional sob o argumento de que, mesmo que as minorias se façam presentes, a decisão sempre caberá à maioria ${ }^{28}$. Essa assertiva é correta, porém está formulada de um modo por demais simplificado.

Ainda que as questôes políticas demandem, forçosamente, uma decisão simplesmente majoritária (Seria um absurdo adotar $70 \%$ de uma proposta e 30\% da contraproposta), a presença de minorias, de oposição, permite Que as Questões sej̧am debatidas com maior profundidade. Presentes, as minorias não podem impor a sua vontade, mas podem debater, negociar, influenciar; ausentes, não podem nada. ${ }^{29}$

Então, pode-se dizer que a discussão teórica acerca da igualdade de voto, em seus dois aspectos formal e material, produz resultados práticos. Porém, a representação de todas as parcelas significativas do eleitorado tem seu custo. Um efeito direto do sistema proporcional é a multiplicidade de partidos, efeito que vai se refletir no funcionamento do governo.

d) Número de partidos. As leis de Duverger. De grande valia foi a observação feita pelo francês Maurice Duverger, tanto que a maioria dos autores a ela se reporta quando

27 Seminário sobre modelos alternativos de representação política no Brasil: realizado na UnB em setembro de 1980, por Afonso Arinos e outros. Brasília: Editora Universidade de Brasília, 1981. Discurso do então senador Tancredo Neves, p. 133-134.

28 VEDEL, citado por BONAVIDES, Ciência Política, 2003, p. 252 e DALLARI, 1998, p. 192.

28 Com posicionamento semelhante, Sully Alves de Souza, Sistemas Eleitorais, in Curso de introdução à ciência política, 1984, p. 80. 
trata dos efeitos do sistema eleitoral sobre o número de partidos. Basicamente, o primeiro dos postulados de Duverger ensina Que, sob um sistema majoritário de um único turno, a tendência dos partidos é de se organizarem em duas grandes agremiações. ${ }^{30} \mathrm{Ou}$ sej̣a, eleições majoritárias de um só turno facilitam a concentração de partidos, facilitam o bipartidarismo. Isso é bastante plausível pois, numa eleição dessas, como já foi visto, os pequenos têm muito pouco espaço, muito poucas chances de vitória, e tendem a se agrupar antes mesmo da disputa eleitoral.

Ainda sobre eleições majoritárias, agora de dois turnos, o ensinamento de Duverger (terceira lei) é de Que, nessa situação, os partidos terão liberdade para existir em grande número no primeiro turno, mas acabarão por se coligar no segundo turno ${ }^{31}$. De fato, na busca por cargos eletivos, a derrota no primeiro turno não significa frustração total porQue associações com outros partidos para o segundo turno podem garantir a participação no governo.

Já sob um sistema proporcional, conforme a segunda lei de Duverger, a organização partidária tende ao multipartidarismo ${ }^{32}$. Isso vai ao encontro do supra exposto, uma vez que, bastando que o partido tenha força eleitoral suficiente (número de eleitores maior que o Quociente eleitoral) ele ocupará cadeiras; não há maior necessidade de se coligar. Assim, nesse contexto, é realmente fácil que partidos sejam criados $^{33}$.

Muitos autores transmitem a idéia de Que o sistema proporcional provoca, necessariamente, uma multiplicação de partidos. Entretanto, como bem salienta Nicolau em estudo minucioso ${ }^{34}$, as regras de Duverger devem ser interpretadas como relações de probabilidade ou tendências, não como relaçóes de causalidade absoluta. Prossegue esse estudioso afirmando Que, no sistema proporcional, ao contrário do majoritário, os partidos não são levados a se coligar. Assim, havendo outras condições favoráveis e não havendo a barreira do sistema majoritário, os partidos, provavelmente, diversificar-se-ão. ${ }^{35}$

Em que pesem as divergências Quanto à causalidade necessária ou simplesmente provável, o fato é que, ao observarem diversos países, muitos autores confirmam a validade dessas regras ${ }^{36}$. A facilidade ou a dificuldade para a criação de partidos, as tendências para o multipartidarismo ou para a concentração de partidos e o bipartidarismo acarretam diversos efeitos, seja diretamente, seja indiretamente.

30 Explicando as leis de Duverger, BASTOS, Celso Ribeiro. Curso de teoria do estado e ciência política. 3. ed. São Paulo: Saraiva, 1995, p. 135-136.

31 Conforme exposto por BASTOS, op. cit., p. 135-136.

12 BASTOS, op, cit., p. 136.

${ }^{33}$ Nesse sentido, BONAVIDES, Ciência Política, 2003, p. 251.

${ }^{4}$ NICOLAU, lauro Marconi. Multipartidarismo e democracia: um estudo sobre o sistema partidário brasileiro. Rio de laneiro: Editora Fundaçăo Getúlio Vargas, [996. p. 45.

35 NICOLAL, op. cit., p. 48.

${ }^{36}$ Como exemplo, FERREIRA, 1975, p. 657-658. 
Conforme notado por Bonavides ${ }^{37}$, facilitado o multipartidarismo, facilitado está o surgimento de novas idéias, mais fáceis são a inovação, a reformulação de idéias e a revisão de conceitos. Outro aspecto trazido por esse autor é que, num sistema proporcional, pela facilidade de criação de partidos políticos, não há muito sentido em grupos ideológicos se manterem na clandestinidade, exercendo pressão dissimulada, pois facilmente podem participar e lutar por cadeiras. ${ }^{38}$

Entretanto, a facilidade de criação de partidos pode levar a situações indesejadas, não só pela possibilidade de, no jogo político, partidos pequenos assumir importância e influência desproporcional à sua representatividade ${ }^{39}$, como pela possibilidade de institucionalização de partidos de ideologias extremistas, fundamentalistas, detentores de opiniões Que beirem a inconstitucionalidade ${ }^{40}$.

Um ponto sobre o Qual a organização partidária exerce relevante influência é a governabilidade, assunto Que merece um maior aprofundamento.

e) Governabilidade. A existência de poucos ou muitos partidos interfere de diversas formas na vida política de um país. Inúmeras Questôes inter-relacionadas surgem Quando se analisam o bipartidarismo (ou concentração de partidos) e o pluripartidarismo.

Dentre tantas Questões destaca-se a influência do número de partidos no funcionamento do governo. Autores referem Que, uma vez inclinado à existência de poucos partidos ou o simples bipartidarismo, o sistema majoritário produz governos estáveis, com visíveis e sólidas maiorias, o Que facilitaria muito o funcionamento do governo ${ }^{41}$. Em contrapartida, o sistema proporcional, pela multiplicidade de partidos, dificultaria a atividade do governo, tornando as negociaçöes mais complexas, mais morosas. ${ }^{42}$

Entretanto, essas observações não devem ser consideradas como absolutas. Não só porque a organização partidária (entenda-se, aqui, número de partidos) depende também de muitos outros fatores, Que năo só o sistema eleitoral, como também pelo fato de que a

37 BONAVIDES, Ciência Política, 2003, p. 251.

38 BONAVIDES, op.cit., p. 251.

39 A respeito disso, BONAVIDES, op.cit., p. 252.

40 Sobre isso, BASTOS, 1995, p. 113.

41 BONAVIDES, op. cit., p. 248

${ }^{42}$ Conforme Azambuja: 'Os Parłanentos eleitos pela R.P. [representação proporcional] segundo as fórmulas mais tecnicamente perleitas, são Parlamentos sem maiorias, o Que torna o governo difícil e a elaboração das leis morosa e desordenada, impossibilitando muitas vezes a adoçáo de medidas necessárias e de uma orientação definida na atividade dos poderes púbicos. Quando, em uma nação, há somente dois ou três grandes partidos políticos, a R.P. funciona com vantagem distribuindo entre eles as vagas sem esfacelar politicamente o Paflamento. Quando, porém, há seis ou oito partidos, o Parlamento se torna un fator de instabilidade, de indecisão e até de perigo para o Estado, cujo governo não dispốe nunca de uma força que o apóie, e fica à mercê de todas as manobras para enfraquecê-lo e derrubá-lo.' (AZAMBUIA, Darcy. Teoria geral do Estado. 42. ed. São Paulo: Globo, 2002, p.342) Também nesse sentido, BONAVIDES, Ciência Política, 2003, p. 252; CAVALCANTI, 1958, p.333-334, e, especialmente, FERREIRA FILHO, 2003, p. 137-139. 
Qualidade de um governo não se mede apenas por sua agilidade. De Qualouer forma, aspectos positivos acompanham a multiplicidade de partidos. Ulysses Guimarães, além de afirmar que o surgimento de partidos num sistema proporcional se dá em número razoável ${ }^{43}$, apontava Que, existindo opiniões divergentes - e de fato existiam e ainda existem -, muito methor Que participem, tenham voz, do Que assumam 'formas subversivas mais perigosas' ${ }^{\text {'44. }}$.

Um aspecto negativo é Que, se participam do governo muitos partidos, torna-se extremamente difficil identificar a opinião do eleitorado e a orientação ideológica Que deveria ser seguida pela maioria Que dá o suporte ao governo, bem como manter uma línha política coerente ${ }^{45}$ Nesse aspecto, o sistema majoritário, com sua tendência ao bipartidarismo, facilita a definição da política a ser adotada e, assim, a responsabilização dos governantes pela coerência ou incoerência de seus atos. ${ }^{46}$

Esse problema e outras Questões, tais como o comportamento dos partidos, sua estabilidade, sua imagem, demandam um estudo muito mais aprofundado do que cabe no presente artigo. Aliás, a reforma política, que está em discussão, além de abordar o sistema eleitoral, aborda toda a organização partidária.

f) Candidato versus partido. Uma outra Questão Que surge do confronto entre o sistema majoritário e o sistema proporcional é a preponderância do partido ou do candidato na opinião, no desejo do eleitor.

No sistema majoritário, evidentemente, a tendência é que o eleitor se preocupe muito mais com o candidato do que com o partido. Eleito será o candidato, Que trará o partido, não o inverso ${ }^{47}$.

Já no sistema proporcional, como o voto num candidato de determinado partido ajuda a todos os candidatos do mesmo partido, a propensão é de que os eleitores se preocupem mais com o partido do que com o candidato, ou, pelo menos, dêem muito mais atenção ao partido nesse sistema ${ }^{48}$.

Dessa relação entre candidato e partido, derivam outras questões. No sistema proporcional, se, de um lado, o partido passa a ter mais peso, de outro, ele próprio, como um todo, passa a depender mais de seus candidatos. Explica-se: no sistema majoritário, todos os

${ }_{43}$ Seminário sobre modelos alternativos de representação política no Brasil: realizado na UnB em setembro de 1980, por Afonso Arinos e outros. Brasília: Editora Universidade de Brasília, 1981. Discurso do então deputado Ulysses Guimarães, p. 142.

${ }^{44}$ Seminário sobre modelos alternativos de representação politica no Brasil: realizado na UnB, em setembro de 1980, por Afonso Arinos e outros. Brasília: Editora Universidade de Brasília, 1981. Discurso do então deputado Ulysses Guimarães, p. 140.

45 Nesse sentido, FERREIRA FILHO, 1998, p. 102-103; DALLAR!, 1998, p. 192.

46 Conforme DALLARI, op. cit., p. 191.

47 Nesse sentido, BONAVIDES, Ciência Política, 2003, p. 248-249.

48 Da mesma forma, MAGALHÄES, 1997, p. 43; Bastos, 1995, p. 113. 
candidatos concorrem entre si, de modo que os partidos, jamais lançam mais que um candidato, porque um prejudicaria o outro; em oposição, no sistema proporcional, Quanto mais candidatos o partido tiver, e Quanto maior for a votação dos seus candidatos, mais o partido ganha. Assim, num primeiro momento, os candidatos de um mesmo partido concorrem juntos, como uma equipe, contra os candidatos dos outros partidos; apenas num segundo momento - abstratamente falando - é Que vão disputar entre si.

Esse fenômeno leva a duas situações: de um lado, permite Que os partidos elejam "certas personalidades ou certos técnicos, destituídos de clientela eleitoral, mas cuja investidura é de interesse partidário" ${ }^{49}$; de outro, pode levar os partidos a buscarem candidatos de grande votação, Que 'puxarão' os outros, mas que não têm afinidade com a ideologia partidária. ${ }^{50}$

\subsection{Síntese do confronto entre os sistemas eleitorais proporcional e majoritánio}

No embate entre o sistema proporcional e o sistema majoritário destaca-se a Questão do papel e da importância dos partidos políticos. Essa éa questão de fundo da Qual derivam as demais.

Conforme exposto no item "f", o sistema majoritário, especialmente se de um único turno, tende a reduzir o número de partidos políticos, ao passo Que o sistema proporcional favorece o surgimento e a conservação dos mais diversos partidos. Em decorrência, o primeiro dificulta a representação de minorias ideológicas, mas favorece o ato de governar; em oposição, o segundo permite a participação de um maior número de correntes políticas, mas sob o risco de prejudicar a governabilidade.

\section{SISTEMA DISTRITAL: MÉRITOS E DEMÉRITOS DESSA CONCEPÇÃO}

O sistema distrital acrescenta um aspecto novo na configuração do sistema eleitoral: o aspecto geográfico. Se, até então, a Questão girava em torno dos critérios de eleição, maior número de votos ou número suficiente de votos, agora, passa a importar onde se dá o voto.

O sistema distrital não necessariamente se opõe aos sistemas majoritário e proporcional (esses, sim, opostos); soma-se a eles. Vigorando o sistema distrital, os eleitores estão vinculados a áreas geográficas delimitadas, os distritos, só podendo votar em candidatos dessas áreas. Em outras palavras, "o colégio eleitoral é dividido em distritos, devendo o eleitor votar apenas no candidato de seu respectivo distrito". 51

\footnotetext{
19 BONAVIDES, op. cit., p. 251.

\$ De forma semethante, MAGALHÁES, op. cit., p. 43-44.

5: DALLAR, $1998, \mathrm{p} .192$.
} 
Uma distinção deve ser feita entre voto distrital e sistema distrital, para Que não se utilize uma mesma expressão para objetos diversos. ${ }^{52}$ Sob o regime do voto distrital, os eleitores só podem votar nos candidatos inscritos numa determinada área territorial, os distritos.

No sistema distrital, além de o voto ser distritalizado, cada um dos distritos tem um número certo de cadeiras a receber, independentemente do resultado da eleiçãa. ${ }^{53}$ A vantagem do sistema distrital é Que os distritos não correm o risco de ficar sem representantes.

O simples voto distrital, desacompanhado do sistema distrital, dependendo do resultado, pode deixar distritos sem representação, simplesmente poroue os candidatos mais votados dos partidos proporcionalmente mais votados podem estar concentrados em poucos distritos.

Atualmente, as eleições para o congresso Nacional submetem-se ao regime do sistema distrital (voto distrital + sistema distrital). Os eleitores só podem votar nos candidatos inscritos em seu Estado (distrito), e cada unidade da Federação possui um número de cadeiras independentemente do resultado da eleição. ${ }^{54}$

As PECs que defendem o sistema misto, pretendem intensificar a divisão territorial, dividindo os Estados em distritos eleitorais menores. Pode-se dizer que o atual sistema distrital implantado é fraco porQue não atinge seus objetivos. Por essa razão, é comum falar (ainda que erroneamente) Que não existe sistema distrital no Brasil. Existe, sim, mas apenas nas eleições para o Congresso Nacional e com distritos muito amplos - os estados-membros.

Conforme Magalhães, o sistema distrital transfere o poder político para as bases locais, aproxima os representantes dos representados e evita a concentração de poder em determinados grupos. ${ }^{55}$ Outra vantagem desse sistema é o menor custo da campanha. ${ }^{56}$ Por sua vez, para os detratores desse sistema ${ }^{57}$, no âmbito restrito dos distrito seria muito mais fácil aos poderosos economicamente exercer sua pressão. A pessoa dos candidatos se beneficiaria em detrimento dos partidos ${ }^{58} \mathrm{e}$ facilitaria a perpetuação de 'caciques poíticos' ou 'oligarquias locais' no poder. ${ }^{59}$

52 Essa distinção é trazida por CUNHA, Sérgio Sérvulo da. O que é voto distrital. Porto Alegre: Sergio Antonio Fabris Editor, 1991, p. 13 e p. 50.

${ }^{3}$ CUNHA, op.cit., p. 13.

5* Para facilitar a leitura, serão utilizadas as expressóes "voto distrital", para signiffcar esse regime de votação desacompanhada de sistema distrital, e "sistema distrital", para signilicar o voto distrital conjugado com o sistema distrital.

${ }_{55}$ MAGALHÄES, 1997, p. 47-49. Segundo Cunka, estando mais próximos representantes e representados, em tese, seria mais fácil policiar a corrupção. ([99], p. 33)

56 DALLAR, 1998, p. 194.

${ }^{57}$ Conforme mencionam DALLARI, op. cit., p. 194; Seminário sobre modelos alternativos de representaçáo política no Brasil: realizado na UnB em setembro de 1980, por Afonso Arinos e outros. Brasília: Editora Universidade de Brasílla, 1981. Discurso do então senador Tancredo Neves, p. 135; BONAVIDES, Teoria do Estado. 4. ed. rev. e ampl.São Paulo: Mahheiros, 2003, p. 259.

58 BONAVIDES, op. cit., p. 259

59 CUNHA, 1991, p.24 e ss.; DALLARJ, op. cit., p. 194; BONAVIDES, op. cit., p. 259. 


\subsection{Possibilidades oferecidas pela idéia distrital}

Ao se acrescentar o elemento territorial nos sistemas eleitorais, pode-se propor três novas sistemáticas de realização das eleições: o simples voto distrital, o sistema distrital puro e o sistema distrital misto. ${ }^{60}$

\subsection{Voto Distrital}

O simples voto distrital - em que o número de representantes de cada distrito dependerá do resultado da eleição - é defendido por Sérgio Sérvulo da Cunha. Como menciona o autor, a adoção dessa sistemática é suficiente para aproximar o eleitor do candidato, tornar a eleição menos dispendiosa e diminuir a competição interna nos partidos. Sem falar Que não inviabillzza um sistema proporcional, permitindo a eleição de minorias. ${ }^{6 !}$

Entretanto, o defeito potencial desse sistema é exatamente o bandeira dos defensores dos sistemas distritais. Por mais que haja uma maior vinculação entre os candidatos e os eleitores, não há garantias de Que cada distrito efetivamente eleja ao menos um representante. Os candidatos mais votados dos partidos Que coneuistam as cadeiras podem estar concentrados em poucos distritos. Ao que tudo indica, o voto distrital perde sentido Quando contraposto ao sistema distrital misto, antes, porém, cabe abordar o sistema distrital puro.

\subsubsection{Sistema Distrital}

A principal razão de se acrescentar o aspecto territorial na sistemática das eleições é o Fato de Que muitas regiōes, seguidamente, ficam sem representantes a elas diretamente vinculados.

$\mathrm{Na}$ configuração do sistema distrital, pode-se estabelecer que os distritos elegerão, cada um, apenas um candidato, ou, ao inverso, cada um, dois ou mais candidatos. Os primeiros são os chamados 'distritos uninominais', Que estão representados por apenas um candidato: os segundos são os 'distritos plurinominais', com mais de um representante.

Evidentemente, sob distritos uninominais, a eleição só poderá se dar pela forma maịoritária. Nesse caso, estarão presentes os defeitos intrínsecos do sistema maj̧oritário, principalmente a dificuldade de representação de minorias ideológicas. ${ }^{62}$ Sob distritos

60 Em termos teóricos, podem-se conceber oito configurações de sistemas eleitorais: voto näo-distrital e sistema maj̧orlírio; voto não-distrilal e sistema proporcional; voto distrital e sistema não-distrital e sistema majoritário; voto distrital e sistema näo-distrital e sistema proporcional; voto distrilal e distritos uninominais com sisterna majoritário; voto distrital c distritos plurinominais com sistema majoritário; voto distrital e distritos plutinominais com sistema proporcional; voto misto. Neste trabalho são abordadas apenas as configurações Que têm sentido prático e possuem defensores.

6) CUNHA, 1991, p. 15-18 e 24.

62 Nesse sentido: DALLARli, 1998, p. 195; CUNHA, 1991, p. 16 e 24 e ss. 
plurinominais, em tese, seria possível o sistema proporcional. Entretanto, conforme já visto (item 2), o sistema proporcional não atinge seu objetivo principal, que é universalizar a representatividade, se forem poucos os cargos a eleger. Tanto é assim Que as propostas de emenda constitucional que defendem o sistema distrital defendem-no conjugado com o sistema majoritário, não com o proporcional.

Entretanto, conforme já referido, distritos plurinominais são pouco viáveis. Em primeiro lugar, porque tornam a eleição muito complexa e trabalhosa; segundo, porQue há um conflito entre a proporcionalidade e a representatividade territorial. Para Que possibilitem um sistema proporcional efetivo, os distritos têm de ser muito grandes, o Que permite que cidades dos distritos fieuem sem representantes, diminuindo os benefícios da distritalidade.

Assim, na maioria das vezes em Que se fala em sistema distrital, subentendem-se distritos uninominais. Porém, esses distritos não dificultam o sistema proporcional. Eles o impedem por completo. Com base nisso, desenvolveu-se a idéia do sistema distrital misto.

\subsubsection{Sistema Misto}

Tendo em vista Que o sistema distrital puro inviabiliza o sistema proporcional, desenvolveu-se um híbrido, que misturasse o sistema distrital com o sistema proporcional. Eis o sistema misto, ou sisterna distrital misto. O grande mérito desse sistema é permitir a coexistência do sistema proporcional com o sistema distrital. Dessa forma, supostamente, estaria garantida a representatividade de todas as parcelas ideológicas, bem como das parcelas territoriais dos eleitores.

Por esse sistema, uma parte das cadeiras é distribuída entre os distritos individualmente e a outra é mantida para toda a circunscrição eleitoral, os distritos conjuntamente. ${ }^{63}$ Ocorre uma mistura do voto/sistema distrital com o voto/sistema não distrital. Assim, o eleitor passa a ter dois votos: um para candidatos de seu distrito, Que se elegerão pelo sistema majoritário; outro para candidatos comuns a todos os distritos, Que se elegerão pelo sistema proporcional. Conjugados assim estariam todos os sistemas eleitorais, no intuito de preservar os benefícios de cada um. ${ }^{64}$

Essa modalidade de sistema distrital é objeto do maior número de Propostas de Emenda à Constituição.

\subsection{Propostas de Emenda à Constituição oue adotam a idéia distrital}

a) Sistema distrital puro: o sistema distrital em sua forma simples é objeto do Projeto de Lei 493/2003, Que tramita na Câmara dos Deputados. Na mesma casa, encontramse duas Propostas de Emenda à Constituição, sob os números 443/97 e 498/02, com a mesma matéria.

63 MAGALHÃES, 1997, p. 51; SILVA, 2004, p. 375.

64 Teoricamente, ainda seria possível conceber um sistema místo com distritos plurinominais. Entretanto, não é uma ídéja a ser levada a sério porque não colhe os benefícios de um sistema nem do outro. 
O Projeto de Lei 493/2003 propõe a adoção de circunscrições - distritos - com oito deputados, eleitos sob o sistema proporcional. Pretende subdividir as atuais circusncrições estaduais que já possuem mais que oito deputados. Em suas razões, esse projeto firma seu compromisso com o sistema proporcional e argumenta com a facilidade Que haverá nas campanhas políticas em que as distâncias a serem percorridas pelos candidatos serão menores.

Se, por um lado, essa proposta pode viabilizar o sistema proporcional, por outro, dado o tamanho dos "distritos", ela permitirá que regiões de um distrito fiquem sem representantes diretos.

b) Sistema distrital misto: juntamente com as propostas Que mantêm o sistema proporcional, esse sistema é objeto do maior número de Propostas de Emenda à Constituição.

Estão arquivadas no Senado as PECs de números 43/96, 42/98 e 47/99; na Câmara, as de números 16/89, 27/91, 89/91, 168/93 e 433/96, bem como o Projeto de Lei número 4/95.

Tramitam, apenas na Câmara dos Deputados, as propostas de números 10/95, 28/ $95,168 / 95,181 / 95$ e 289/95, todas defendendo um sistema misto com parte das cadeiras escolhidas sob o sistema majoritário em distritos uninominais e parte sob o sistema proporcional.

É possível conceber, teoricamente, outras configurações de sistema misto, entretanto, na prática, perderiam seu sentido de ser. Qualouer sistema misto em Que as cadeiras relativas à circunscrição comum a todos os distritos não sejam preenchidas pelo sistema proporcional simplesmente não tern sentido prático. Adotar o sisterna proporcional em distritos e na circunscrição comum, além de tornar muito complexo e esbarrar na pouca compatibilidade do sistema distrital com o proporcional, tiraria a necessidade do voto misto, posto Que o sistema proporcional já seria adotado.

Por óbvio, entăo, Quando se fala em sistema misto, entende-se voto majoritário nas circunscriçôes, e proporcional nos distritos. E o principal argumento encontrado nas propostas em tramitação é a soma dos benefícios dos sistemas distrital e proporcional.

\subsection{Síntese do embate entre as três idéias distritais}

O ponto pacífico entre as três modalidades distritais é a aproximação dos eleitores com os candidatos. E isso está no alcance de todas elas.

Entretanto, há uma defesa muito forte para não apenas aproximar candidato e eleitor, mas tambérn vincular cada candidato a uma região geográfica, a um distrito. Em outras palavras, são bons os argumentos para assegurar participação eleitoral a todas as áreas territoriais. Com isso, busca-se garantir representatividade a todas as parcelas do eleitorado. Porém, enquanto o sistema proporcional divide o eleitorado em grupos ideológicos, o sistema distrital divide-o em regiōes território (urna ou mais cidades). 
Esse segundo estádio, de representatividade efetiva das parcelas territoriais, só estará garantido Quando além do voto distrital, adotar-se o sistema distrital.

Contudo, o sistema distrital entra em cena ofuscando o sistema proporcional. Estabelece-se um novo conflito: representatividade das parcelas ideológicas do eleitorado versus representatividade das parcelas regionais do eleitorado. Essa é, no entendimento deste estudo, a grande cuestão a ser decidida na reforma do sistema eleitoral.

Oportuno, agora, revisar a reforma do sistema eleitoral como um todo.

\section{DA ESCOLHA DA PROPOSTA DE REFORMA DO SISTEMA ELEITORAL}

Da reforma política Que tramita no Congresso Nacional, a parte que diz respeito à reforma do sistema eleitoral de composição da Câmara dos Deputados concentra-se sobre cuatro grupos de Propostas de Emenda à Constituição da República.

Num primeiro grupo estão as proposições eue defendem reparos nos sistema atual, porém mantêm a proporcionalidade na atribuição de cadeiras; um segundo grupo, visivelmente minoritário, sugere a adoção de um sistema majoritário, nos moldes do adotado para o Senado Federal; o terceiro grupo, também minoritário, abrange as propostas de adoção de um sistema distrital puro; por fim, o Quarto grupo, maior e mais forte, propõe um sistema distrital misto.

Se o sistema eleitoral não influenciasse nem sofresse influência de outras Questões da reforma política e pudesse ser escolhido de forma individualizada, o problema não seria muito diff́cil de resolver; bastaria resolver duas Questões fulcrais.

A primeira delas é sobre a necessidade ou não da adoção de critérios proporcionais, em outras palavras, dimensionar o valor do sistema proporcional. Tendo-se por imprescindível essa sistemática, restringem-se as opções de escolha à manutenção do sistema atual ou ao sistema misto; relativizando-o, abrem-se as vias do sistema distrital puro e do sistema mą̣oritário.

No Que diz respeito à idéia distrital - a segunda Questão -, é necessário debater os benefícios da divisão territorial, e, com isso, dimensionar o valor da distritalização.

Da ponderação dos resultados das avaliações, resultará a indicação de uma da propostas existentes. A partir daí, restariam apenas questões técnicas de operacionalidade e equilíbrio do sistema eleitoral.

Entretanto, a escolha deste ou dacuele sistema influencia e é influenciada por inúmeras outras Questōes. Dessas Questões, uma aparenta ser prejudicial - no sentido processual de ter de ser resolvida por primeiro - a cualeuer abordagem sobre o sistema político. Trata-se da natureza do mandato político, ou, em outras palavras, do papel e do fundamento da representação, eue pode variar de casa para casa e é diferente entre os poderes. Inicialmente, 
isso remete à velha dicotomia entre mandato imperativo e mandato livre, Que, atualmente, seria mais coerentemente apresentada como uma diferenciação gradativa entre a maîor e a menor liberdade de atuação do representante perante a vontade do eleitor. Isso vai refletir diretamente noutro ponto discutido na reforma política: a revogação dos mandatos.

Ainda no Que diz respeito ao mandato político, cabe definir se o voto do eleitor é dado à pessoa do candidato ou ao partido do candidato; cabe definir se quem tem direito à cadeira é o candidato ou o partido. Esse ponto literalmente influencia e é influenciado pela escolha do sistema proporcional. Por sua vez, relaciona-se intimamente com outro ponto da reforma política, a chamada 'fidelidade partidária'.

Superada essa questão, cabe definir o alcance do disposto no art. 45 da Constituição da República, ao definir os deputados como representantes do povo. Cada deputado representaria o povo como um todo indistinto, ou o conjunto de deputados representa o povo por inteiro, mas cada deputado está mais relacionado a uma fração do povo ${ }^{65}$ ? A resposta a essa Questão irá dizer se os deputados federais representam os interesses nacionais ou locais, o Que é fundamental para se determinar a validade de um sistema com critérios distritais.

Também deve ser Questionado se os grupos de eleitores a serem representados devem ser identificados por suas ideologias ou por suas localizações geográficas.

Por fim, resta outra Questão relevante: os partidos. A começar pela identidade dessas agremiações políticas. Assunto corrente, a reforma partidária passa por uma definição das reais diferenças ideológicas dos partidos e de suas efetivas propostas políticas. Novamente é uma Questão intimamente ligada ao tema desse trabalho, pois, conforme já visto, os sistemas eleitorais influenciam no número de partidos existentes.

As questóes expostas e a relação existente entre elas evidenciam a necessidade de uma abordagem ampla e cuidadosa da reforma do sistema eleitoral, a Qual considere os outros aspectos do sistema político. Tanto melhor será o desfecho da reforma política e do sistema eleitoral Quanto mais claras e coerentes forem as respostas dadas aos problemas citados.

O número de partidos e o grau de liberdade dos representantes frente aos eleitores e seus partidos influenciam diretamente o funcionamento do governo, a governabilidade ${ }^{66}$. Mas, mais do Que isso, a sensação de estar representado e a efetiva participação política dos eleitores são a meihor garantia de estabilidade social.

as Relacionado com uma parcela do povo năo só de fato, como já o é, mas também de direito.

66 Sobre a relação entre partidos políticos, ver, especialmente capítulo três, de SOUZA IUNIOR, Cezar Satdanha de. Consenso e Tipos de Estado no Ocidente. Porto Alegre: Editora Sagra Luzzatto, 2002. 


\section{CONCLUSÃo}

Dois são os sistemas eleitorais clássicos.

Pelo primeiro, baseado na sistemática da tomada de decisões, vencem os candidatos com maiores votações. Trata-se do sistema majoritário.

No segundo, em que o objetivo é garantir representatividade à todas as parcelas (ideológicas) significativas do eleitorado, as cadeiras são distribuídas entre os partidos na proporção de suas votações, sendo Que não necessariamente os candidatos mais votados é Que se elegem. Eis o sistema proporcional.

Um terceiro fator pode ser acrescentado: a divisão do território em distritos eleitorais. Seja por simples vinculação dos eleitores aos candidatos de seu distrito (simples voto distrital), seja por garantir um número de cadeiras a cada distrito (sistema distrital puro), ou, ainda, por atribuir uma parte das cadeiras individualmente aos distritos e outra ao conjunto como um todo (sistema distrital misto).

A escolha de um sistema eleitoral, se pudesse ser realizada isoladamente, começaria pela permanência ou abandono da idéia de proporcionalidade e acabaria na valoração da representação vinculada a parcelas da população territorialmente distintas.

Entretanto, o sistema eleitoral está intimamente relacionado diversos fatores, condicionando-os e sendo condicionado por eles. Assim, a definição do sistema eleitoral deve vir acompanhada de uma visão do todo político, a reforma no sistema eleitoral deve harmonizar-se com os institutos políticos atuais ou vir acompanhada de um projeto geral $\mathrm{e}$ sistemático de reforma política. O sistema eleitoral não pode, de modo algum, ser escolhido de forma isolada e não sistemática.

O sistema político, no Qual se insere o sistema eleitoral, é como uma complexa engrenagem, em Que o ajuste de uma mola pode desregular outra ou emperrar o mecanismo se não for acompanhada do ajuste de outras peças e da constante manutenção do todo.

\section{A opiniāo do autor}

A reforma política, encarada em seu conjunto total, deve ter dois objetivos fundamentais: a) procurar conferir maior legitimidade política aos representantes e à atuação como representantes, isto é, tornar a democracia ainda mais democrática no sentido de maior legitimidade; b) melhorar o funcionamento do sistema, tornando-o mais eficaz, de modo a propiciar uma governabilidade mais produtiva e eficiente.

Os pontos específicos da reforma política dirigem-se mais a um ou a outro dos objetivos fundamentais. A uma primeira vista, a reforma do sistema eleitoral, objeto deste estudo, está mais relacionada com a legitimidade da representação política. Entretanto, ainda Que as Questões específicas se atenham mais a esse determinado ponto, nenhuma delas pode desconsiderar o necessário equilibrio entre legitimidade e operacionalidade. 
Apesar das conclusōes atingidas pelo presente trabalho, pelas Quais se evidenciou Que a reforma do sistema eleitoral está tão relacionada a outras Questões Que não se pode pretender decidi-la isoladamente, faz-se necessária a tomada de um posicionamento em relação ao presente estudo, como forma de iniciar o debate da reforma política.

Sem pretensões de definitividade e ciente das opiniões divergentes de renomados autores, sugere-se o sistema distrital puro, com distritos uninominais e sistema majoritário de dois turnos para a composição da Câmara de Deputados e das Assembléias Legislativas. Esse posicionamento fundamenta-se em três motivos.

Primeiro, a falácia do sistema proporcional na conjuntura hodierna ${ }^{67}$ Propagandeado como meio de acesso às minorias, ele serve muito mais aos partidos como agremiações de interesses do Que às supostas minorias ideológicas. Explica-se: atualmente, os partidos políticos não possuem uma identidade ideológica clara e definida. Paralelamente, na complexidade das Questões atuais, é difícil adotar uma ideologia, ou melhor, é difícil formular uma corrente ideológica Que se aplique a Questões tão diversas como aborto, relações homoafetivas, política macroeconômica, relações exteriores. Posição ideológica clara e coerente, atualmente, só é possível de uma forma muito ampla e vaga. Então, os partidos não só não representam correntes ideológicas coesas e precisas como dificilmente conseguirão isso. A chamada 'representatividade das minorias' no sistema proporcional mais parece um pretexto para facilitar a obtenção de cadeiras pelos grupos de interesses. Assim, o sistema proporcional não é o grande instrumento da democracia, como alguns afirmam.

Segundo, a descrença na eficácia do sistema distrital misto. Combinar o sistema proporcional com o sistema distrital, elegendo metade das cadeiras por um e metade por outro, não parece ser a solução ideal. É bem sabido Que, para o bom funcionamento dąuele sistema, é necessário o maior número de cargos a eleger; outrossim, esse tem mais utitlidade Quanto maior for o número de distritos. O equilibrio entre ambos pode significar a inefetividade de ambos.

Por fim, os méritos do sistema distrital, Que o levam a vencer o confronto com o sistema proporcional. O maior de todos é conferir efetiva representatividade ao povo, ou sej̣a, só o sistema distrital permite Que todas as parcelas dos eleitores tenham representantes. Não se está falando em parcelas ideológicas, o Que é uma ficção, mas em parcelas territoriais, em conjuntos de pessoas com interesses pessoais geograficamente próximos. Com isso. consegue-se um maior poder nas mãos do eleitor e um maior controle sobre o representante, pois um deputado vinculado a uma cidade tem a sua atuação facilmente controlada. Assim, desagradando a maioria dos eleitores de seu distrito, não será reeleito. Até mesmo as Questões de fundo mais ideológico passam a ser decididas de forma democrática, mais efetivamente ligada à real opinião do povo.

67 Esse motivo é a principal premissa da defesa do sistema distrital puro. Não aceita essa premissa, fácil é rejeitar a conclusão - posicionamento. 
Entretanto, tanto mais efetivo é o sistema distrital Quanto menores forem os distritos e, Quanto maior for a Quantidade, menor será o tamanho. Também por isso é que é desaconselhável o sistema misto.

Por fim, defende-se a sistemática de dois turnos para, de um lado, permitir a existência de vários partidos e, de outro, conferir maior legitimidade ao representante, para que não fieue como alguns senadores Que representam toda a população de um Estado, tendo recebido votos de uma ínfima parcela da população.

\section{REFERÊNCIAS BIBLIOGRÁFICAS}

AMADO, Gilberto. Eleições e representação. Brasília: Senado Federal, 1999.

AZAMBUIA, Darcy. Teoria geral do Estado. 42. ed. São Paulo: Globo, 2002.

BASTOS, Cesso Ribeiro. Curso de Teoria do Estado e Ciência Política. 3. ed. São Paulo: Saraiva, 1995.

BONAVIDES, Paulo. Ciência Política. 10. ed. rev. atual. São Paulo: Maiheiros, 2003. . Teoria do Estado. 4. ed. rev. e ampl.São Paulo: Malheiros, 2003.

CAVALCANTI, Themistocles Brandão. Teoria do Estado. Rio de Janeiro: Editor Borsol, 1958. Editor, 1991.

CuNHA, Sérgio Sérvulo da. O que é voto distrital. Porto Alegre: Sergio Antonio Fabris

Curso de introdução à ciência política. 2. ed. Brasília: Editora Universidade de Brasília, 1984. v.4. (Voto c representação, Vicente Barreto) (Sistemas Eleitorais, Sully Alves de Souza)

DALLARI, Dalmo de Abreu. Elementos de teoria geral do Estado. 20. ed. atual. São Paulo: Saraiva, 1998.

FERREIRA, Luís Pinto. Teoria geral do Estado. 2. ed. rev. ampl. e atualizada. São Paulo: Saraiva, 1975.v. 2.

FERREIRA FILHO, Manoel Gonçalves. Comentários à Constituiçăo brasileira de 1988. 2. ed. atual. e reformulada. São Paulo: Saraiva, 1997.

FERREIRA FILHO, Manoel Gonçalves. Curso de direito constitucional. 9. ed. ampl. e atual. de acordo com as Emendas Constitucionais e a Revisão Constitucional pelo autor. São Paulo: Saraiva, 1998.

MAGALHÃES, José Luiz Quadros de. Debates de direito eleitoral. Belo Horizonte: Movimento editorial Faculdade de Direito da UFMG. 1997.

MALUF, Sahid. Teoria geral do Estado. 24. ed. rev. e atuual. / pelo Prof. Miguel Alfredo Malufe Neto - São Paulo: Saraiva, 1998.

NICOLAU, Jauro Marconi. Multipartidarismo e democracia: um estudo sobre o sistema partidário brasileiro. Rio de laneiro: Editora Fundação Getúlio Vargas, 1996. 
PAUPERIO, A. Machado. Teoria geral do Estado. 6. ed. rev. e ampl. Rio de Janeiro, Forense, 1971.

Seminário sobre modelos alternativos de representação política no Brasil: realizado na UnB, em setembro de 1980, por Afonso Arinos e outros. Brasília: Editora Universidade de Brasítia, 1981.

SILVA, losé Afonso da. Curso de direito constitucional positivo. 23. ed. São Paulo: Malheiros, 2004.

SOUZA JUNIOR, Cezar Saldanha. Consenso e Tipos de Estado no Ocidente. Porto Alegre: Editora Sagra Luzzatto, 200.

STRECK, Lento Luiz e MORAIS, José Luis Bolzan de. Ciência política e teoria geral do estado. 3. ed. Porto Alegre: Livraria do Advogado, 2003.

STRECK, Lenio Luiz. Hermenêutica lurídica e(m) Crise. 5. ed. rev. atual. Porto Alegre: Livraria do Advogado, 2004.

Projetos de Lei e Propostas de Emenda à Constituição no Senado Federal: disponíveis em $<$ www.senado.gov.br> Acesso em 9.mar.2005.

Projetos de Lei e Propostas de Emenda à Constituição na Câmara dos Deputados: disponíveis em < www.camara.gov.br> Acesso em 9.mar.2005. 